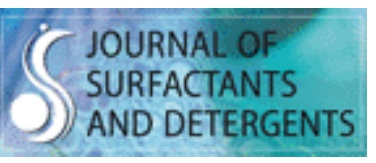

On the relationships between the hydrophilic-lipophilic balance and the nanoarchitecture of nonionic surfactant systems

\begin{tabular}{|c|c|}
\hline Journal: & Journal of Surfactants and Detergents \\
\hline Manuscript ID & Draft \\
\hline Manuscript Type: & Short Communication \\
\hline $\begin{array}{r}\text { Date Submitted by the } \\
\text { Author: }\end{array}$ & $n / a$ \\
\hline Complete List of Authors: & $\begin{array}{l}\text { Rodriguez-Abreu, Carlos; Institute for Advanced Chemistry of Catalonia, } \\
\text { CSIC, }\end{array}$ \\
\hline Keywords: & Non-ionic surfactants \\
\hline
\end{tabular}




\title{
On the relationships between the hydrophilic-lipophilic balance and the nanoarchitecture of nonionic surfactant systems
}

Short Running title: HLB and packing parameter in nonionics

Carlos Rodríguez-Abreu

Instituto de Química Avanzada de Cataluña, Consejo Superior de Investigaciones Científicas (IQAC-CSIC) and CIBER de Bioingeniería, Biomateriales y Nanomedicina (CIBER-BBN), Jordi Girona 18-26, 08034 Barcelona, Spain

carlos.rodriguez@,iqac.csic.es

Acknowledgments: the author is grateful to CSIC (Spain) for financial support through the I-LINK program (Grant I-LINK1188)

\begin{abstract}
Building links between established parameters for the characterization of surfactant systems is useful not only for the understanding of the underlying phenomena but also for the judicious formulation of products. Herein, we review comprehensively literature data to find correlations between the hydrophilic-lipophilic balance (HLB) and the molecular packing parameter $(P)$ for a variety of nonionic surfactants in water. The interfacial area per surfactant molecule, a fundamental variable to calculate $P$, follows a power law as a function of the number of ethylene oxide groups in the surfactant. The exponent ranges from 0.3 to 0.7 which may reflect changes in the conformation of the ethylene oxide chain depending on the nature of the hydrophobic group; there is also apparently a transition towards a collapsed conformation of the ethylene oxide chains at high surfactant concentrations. $P$ is found to change linearly with HLB in the range of data studied, although the parameters of the linear fitting depend on the nature of both hydrophobic and hydrophilic moieties of the surfactant; this would also imply a linear relationship between $P$ and the HLB temperature (i.e. Phase Inversion Temperature) according to the Kunieda-Shinoda equations. Analysis of the liquid crystal regions of the surfactant phase diagram at constant temperature indicate that the HLB values required for the morphological phase transitions defined by $P$ increase with surfactant concentration. The present report may serve as contribution for the programmed design of nanoarchitectures in surfactant systems.
\end{abstract}


Keywords: Nonionic surfactants, Hydrophilic-Lipophilic Balance, HLB, Packing parameter, Phase behavior; Phase diagrams.

\section{Introduction}

From long ago, efforts have been devoted in academy and industry to establish structureproperty relationships in surfactants (Davis, 1994; Rodríguez-Abreu, 2014). The empirical HLB scale (Griffin, 1949, 1954) is one of the earliest attempts in such direction. It has the advantage of being in principle easy to estimate from a simple equation that is linear and depends only on the weight fraction of hydrophilic groups in the surfactant molecule. Accordingly, low HLBs correspond to hydrophobic surfactants whereas high HLBs correspond to hydrophobic surfactants. However, the HLB scale was initially restricted to certain non-ionic surfactants at room temperature. Moreover, the estimated HLB may be the same for two surfactants that yet may behave differently because of dissimilarities in their chemical structure. Accordingly, other methods different from the Griffin equation were proposed to estimate HLB number (Davies, 1957; Ben-Et, 1972; Rabaron et al., 1993) so that the scale has been extended to ionic surfactants. Later on, more systemic and comprehensive formulation parameters for oil/water/surfactant mixtures have been developed such as the SAD (Surfactant Affinity Difference) and HLD (Hydrophilic-Lipophilic Deviation) concepts (Salager, 2000; Queste, 2007; Acosta, 2008), which take into account effects not considered in the HLB scale such as temperature, salinity, type of oil and cosurfactants. Still, the HLB scale continues to be used in commercial products as a selection guide and therefore is of practical relevance.

A different approach based on a theory linking together thermodynamics, interaction free energies and molecular geometry resulted in the introduction of the surfactant molecular packing parameter $P$ (Israelachvili, 1976). This parameter has been successfully used for the qualitative description and prediction of nanostructures, not only in surfactant solutions but also in surfactant-derived inorganic materials (Huo,1996).

There have been some attempts to link the surfactant parameters described above. Kunz et al (Kunz, 2009) proposed an equivalence between the spontaneous curvature, the molecular packing parameter, and HLD. Those authors however focused on a particular system, the pentaethylene glycol monododecyl ether/water/n-octane system. 
Besides the work of Berger et al (Berger, 2005), there is not much literature on the correlation between HLB and $P$ despite they are two relevant surfactant characterization parameters. Herewith, that earlier work is extended to a wider library of experimental data with the aim of filling that gap for the case of nonionic surfactants in water. The interfacial area of the surfactant in aggregates is considered as a key parameter as it much reflects changes in physicochemical conditions and formulation. Further, the important effect of surfactant concentration is considered in the analysis through the use of phase diagrams.

\section{Results and discussion}

The packing parameter $P$ (Israelachvili, 1976) is expressed as

$$
P=\frac{V}{a l}
$$

Where $V$ and $l$ are the volume and length of the hydrophobic moiety, respectively, and $a$ is the cross sectional area of the surfactant at the interface. The critical values for morphological transition are $P=1 / 3$ for spheres, $P=1 / 2$ for cylinders and $P=1$ for planar bilayers. $P$ is also related with the surfactant layer curvature, so that for $P<1$ the curvature is positive, for $P=1$ is zero and for $P>1$ is negative.

In the case of alkyl-type hydrophobic moieties, $V$ and $l$ can be estimated by the following equations (Tanford, 1972)

$$
\begin{aligned}
& V=27.4+26.9 \mathrm{~N} \\
& l=1.4+1.255 \mathrm{~N}
\end{aligned}
$$

where $N$ is the number of carbons in the alkyl tail. Eq. 3 actually gives the maximum length of the chain, i.e. in its fully extended conformation.

$a$ is a parameter more difficult to estimate, since compared to $V$ and $l$, it depends much more on physicochemical variables. In the case of nonionics, $a$ changes with the size of the hydrophilic moiety, temperature and surfactant concentration, therefore is a key parameter that determines the nanoarchitecture of surfactant systems.

Although not completely realistic, a first approximation is to take $a$ as the limiting area at the saturated air/water interface $\left(a_{s}\right)$, i.e. at the critical micellar concentration (CMC); there is 
plenty of experimental data on $a_{s}$ from surface tension and neutron reflectivity measurements. As for the dependence on the size of the hydrophilic moiety, the conformation of poly(oxyethylene) chain is expected to play an important role; this conformation is described by the mean field theory of polymer solutions in which polymers are considered as random walks. Accordingly, the radius of gyration $\left(R_{g}\right)$ scales with the degree of polymerization $n$ as $R_{g}=n^{v}$, where $v$ is the excluded volume exponent which is $3 / 5$ for fully swollen chains, $1 / 2$ for Gaussian chains, and 1/3 for fully collapsed chains (Hammouda, 2007).

In the case of alkyl polyethoxylates $a_{s}$ has been found (van Voorst, 1960; Nikas, 1992) to follow a power law as a function of the number of ethylene oxide groups in the surfactant molecule $(n)$, i.e. $a_{\mathrm{s}}$ can be expressed as

$$
a_{s}=k n^{x}
$$

Eq. 4 is in agreement with the scaling law followed by $R_{g}$, in despite that the poly(oxyethylene) chains in surfactants are relatively short (oligomeric). Early reports have suggested that $x=1 / 2$ and actually this value can be predicted if its assumed that only hydration water remains in the saturated surfactant layer at the water/air interface, and that the poly(ethylene oxide) (EO) chains behave like a Gaussian coil which keeps its size when constrained in the surfactant layer. If other scaling formulas for flexible chains in a good solvent are considered, then $x$ is found to be 6/11 (Sedev, 2001), which is still close to $1 / 2$. Available experimental data of $a_{s}$ at $25^{\circ} \mathrm{C}$ were fitted to Eq. 4 and the values of $k$ and $x$ obtained are shown in Table 1 for different nonionic surfactant series (note that both surfactants with homogeneous and polydisperse ethylene oxide chains are included). The fitting is good as indicated by $R^{2}$ values close to 1 ; values of $x$ range from 0.3 to 0.7 , suggesting that the conformation of EO chains and therefore $a_{s}$ depend on the hydrophobic group of the surfactant. For example, in fluorinated surfactants $\mathrm{x}$ is low pointing to a nearly collapsed EO chain conformation induced by a very dense packing at the interface (Matos, 1989)

Insert Table 1 
Fitting the data of $\mathrm{C}_{\mathrm{j}} \mathrm{EO}_{n}$ surfactant areas at the water/octane interface $(\mathrm{j}=6,8,10,12$ and $n=$ 2,3,4,5,6) calculated from Small-Angle Neutron Scattering (SANS) measurements (Sottmann et al, 1997), the values of $k$ and $x$ are estimated at 29.66 and 0.44 , respectively.

In comparison to $a_{s}$, the values of interfacial areas are actually lower in the aggregates and especially at higher surfactant concentrations, i.e. in the liquid crystal region of the surfactant/water phase diagram. Still, Eq. 4 gives a good fit to the data as shown in Fig.1. For the case of $\mathrm{C}_{12} \mathrm{EO}_{\mathrm{n}}$ surfactant series, $x$ appears to decrease with surfactant concentration.

\section{Insert Figure 1}

Results from fitting to other non-ionic surfactant systems at high concentrations i.e., in the liquid crystal regions of the surfactant/water phase diagram, are summarized in Table 2. Note the $x$ values are lower than in table 1, which may be attributed to a nearly collapsed conformation of the EO chain when confined in the packed layers of liquid crystals at high surfactant concentrations.

\section{Insert Table 2}

Again as a first approximation, the values of $a_{s}$ (air/water interface) are taken to calculate the packing parameter $P$ from Eqs. 1-3. The Griffin equation (Eq. 5) is then used to construct a plot of $P$ versus HLB for different surfactants series as shown in Fig. 2.

$$
\mathrm{HLB}=\frac{w t \% \text { hydrophilic moiety }}{5}
$$

From Eq. 4 and 5, one would expect a non-linear relationship between $P$ and HLB for this type of surfactants. However, as can be seen in Fig.2, in practical terms the data fits well to a linear trend with negative slope for all the surfactants series considered and within the given HLB range. Fig. 2 also shows schematically the loci for the morphological transitions in aggregates: bilayers are favored at low HLB, cylinders at intermediate HLB and spheres at high HLB.

Insert Figure 2 
Results from the fittings in Fig.2 are summarized in Table 3. It is evident that the data in Fig. 2 does not collapse in a single curve but the packing parameter is determined not only by the mass ratio of the hydrophobic and hydrophilic moieties (i.e. HLB) but also by the chemical nature of both moieties in the surfactant molecule (Nagarajan, 2002). For instance, the packing parameter of surfactants with polyglucoside as hydrophile appears to change much less with HLB than those bearing a poly(ethylene oxide) hydrophile. Also, keeping HLB constant, it is possible to have a cylinder-bilayer transition by increasing the length of the hydrophobe in $\mathrm{C}_{\mathrm{j}} \mathrm{EO}_{n}$ surfactants.

At this point, it is also possible to make equivalencies with another surfactant characterization parameter, the phase inversion temperature (PIT) or HLB temperature $\left(T_{H L B}\right)$, extending this way the approach to surfactant/oil/water systems. In many systems $T_{H L B}$ changes linearly with HLB according to:

$$
T_{H L B}=k_{\text {oil }}\left(\mathrm{HLB}-N_{\text {oil }}\right)
$$

Where $k_{\text {oil }}$ and $N_{\text {oil }}$ are constants for a given oil (Kunieda, 1985). Eq.6 and Table 3 then indicate that there will also be a linear relationship (with negative slope) between $T_{H L B}$ and $P$, i.e. low $T_{H L B}$ at high $P$ and high $T_{H L B}$ at high $P$.

\section{Insert Table 3}

Now comes the analysis of the effect of surfactant concentration. The analysis will be based on the Kunieda's phase diagrams, i.e. isothermal diagrams showing the phase regions as a function of the hydrophilic volume fraction in the surfactant and the surfactant concentration (in weight fraction). Herewith, the hydrophilic volume fraction has been replaced by the HLB (estimated by Eq.5), as seen in Fig.3,5 and 6. In these figures, the subscript 1 denotes "hydrophilic" or "normal"-type self-organizing structure or phase, in which the average curvature of surfactant layer is positive and convex toward water. The subscript 2 indicates "lipophilic" or "reverse"- type assemblies. $\mathrm{H}_{1}$ is a hexagonal liquid crystal; $\mathrm{H}_{2}$ is a reverse hexagonal liquid; $I_{1}$ is a micellar cubic phase; $I_{2}$ is a reverse micellar cubic phase; $V_{1}$ is a bicontinuous cubic phase; $\mathrm{V}_{2}$ : is a reverse bicontinuous cubic phase; $\mathrm{L}_{\alpha}$ is a lamellar liquid crystal: $\mathrm{D}_{2}$ is a isotropic bicontinuous surfactant phase (reverse type), also denoted by D' or $\mathrm{L}_{3}$ phase (Kunieda, 1982,Strey et al, 1990); $\mathrm{N}$ is a nematic phase; $\mathrm{W}_{\mathrm{m}}$ is an aqueous micellar 
phase; $\mathrm{O}_{\mathrm{m}}$ is an oily phase such as a reverse micellar solution phase or liquid surfactant; W is an excess water phase; $\mathrm{S}$ is a solid-present region.

For $\mathrm{C}_{\mathrm{j}} \mathrm{EO}_{n}$ surfactants (Fig.3), it is evident that the morphology and structure of surfactants aggregates and liquid crystals are dependent not only on concentration and HLB, but also on the length of the alkyl chain. On one hand, at constant HLB, a $\mathrm{I}_{1}$ to $\mathrm{H}_{1}$ transition $(P=1 / 3$ to $P$ $=1 / 2$ ) is driven by an increase in surfactant concentration for $\mathrm{j}=12,16$ and 18:1. Also, an increase in surfactant concentration induces a $\mathrm{H}_{1}$ to $\mathrm{L}_{\alpha}$ transition $(P=1 / 2$ to $P=1)$ for $\mathrm{j}=12$ and 18:1. On the other hand, at constant surfactant concentration, there are a $\mathrm{I}_{1}$ to $\mathrm{H}_{1}$ to $\mathrm{L}_{\alpha}$ transitions $(P=1 / 3$ to $P=1 / 2$ to $P=1)$ by decreasing HLB for $\mathrm{j}=12$ and $18: 1$. Reverse structures with negative curvature such as the $\mathrm{H}_{2}$ phase $(P>1)$ are also possible for $\mathrm{j}=18: 1$ at surfactant weight fractions higher than ca. 0.6 and HLB $<8$

\section{Insert Figure 3}

The boundaries for morphological transitions in the liquid crystal regions for $\mathrm{C}_{\mathrm{j}} \mathrm{EO}_{n}$ surfactants as a function of HLB and surfactant concentration derived from Fig.3 are summarized in Fig. 4. The HLB required for the layer-to-cylinder transition $(P=1$ to $1 / 2)$ increases non-linearly with surfactant concentration, and it is approximately in the range HLB $=10-15$, i.e. surfactants with $\mathrm{HLB}<10$ would tend to form bilayers or other structures with low curvature. The HLB required for cylinder-to-sphere transition $(P=1 / 2$ to $1 / 3)$ also increases non-linearly with surfactant concentration and it is approximately in the range HLB $=12-17$.

\section{Insert Figure 4}

The HLB vs surfactant concentration phase diagrams were also constructed for other type of nonionic surfactants. When a trisiloxane chain is present as the hydrophobic moiety in the nonionic surfactant molecule, the $\mathrm{L}_{\alpha}$ phase $(P=1)$ tends to shift to higher HLB values as compared to $\mathrm{C}_{\mathrm{j}} \mathrm{EO}_{n}$ surfactants (Fig.5a); actually, the $\mathrm{L}_{\alpha}$ phase (bilayer) is dominant in the phase diagram of trisiloxane nonionic surfactants. For longer siloxane chains (Fig.5b) structures with lower curvature are preferred and it is possible to form reverse structures such as $\mathrm{H}_{2}$ and $\mathrm{I}_{2}(P>1)$ at $\mathrm{HLB}<7$ and surfactant weight fractions higher than ca. 0.7. Note the existence of liquid crystals in siloxane surfactants at $\mathrm{HLBs}<5$, something not found in $\mathrm{C}_{\mathrm{j}} \mathrm{EO}_{n}$ 
surfactants. Contrary to alkyl chains, very long poly(dimethylsiloxane) remain in the liquid state. This allows a wider range of hydrophobicity in aggregates and therefore stronger segregation between the poly(dimethylsiloxane) and poly(ethylene oxide) chains, which favors the formation of reverse liquid crystals.

\section{Insert Figure 5}

A change of the type of nonionic hydrophilic group also impacts the relationship between HLB and $P$, as shown in the phase diagram for polyglyceryl surfactants(Fig.6). In this case, there is no formation of $\mathrm{I}_{1}$ phase and in general there is much less variety of surfactant selfassembled structures as compared to $\mathrm{C}_{\mathrm{j}} \mathrm{EO}_{n}$ surfactants (Fig.3). Poly(glycerol) and poly(ethylene oxide) have different hydration properties, which affects their phase behavior. For example, the cloud point of polyglyceryl surfactants increases much more with HLB than that of $\mathrm{C}_{\mathrm{j}} \mathrm{EO}_{n}$ surfactants (Kunieda, 2002).

\section{Insert Figure 6}

\section{Conclusions and Outlook}

Literature data on several nonionic surfactants in water have been fitted to produce power laws for the interfacial area in aggregates and then empirical linear equations between the hydrophile-lipophile balance (HLB) and the molecular packing parameter $(P)$, which also implies linear correlations with the HLB temperature or phase inversion temperature. The parameters of the linear equations depend both on the hydrophilic and hydrophobic groups of the surfactant molecule. The analysis of phase diagrams at constant temperature in the concentrated region indicate that the HLB required for the cylinder-to-sphere $(P=1 / 2$ to $1 / 3)$ or layer-to-cylinder transitions $(P=1$ to $1 / 2)$ increases with surfactant concentration.

The present approach may serve as contribution for the programmed design of nanoarchitectures in surfactant systems. If appropriate equations are derived to estimate the interfacial area and effective hydrophobic length and volume, HLB- $P$ relationships could in principle also be established for ionic surfactants and surfactant/water/oil systems, but it is a challenge. 


\section{References}

1. Acosta, E.J. \& Bhakta, A.S. (2008) The HLD-NAC model for mixtures of ionic and non-ionic surfactants. Journal of Surfactants and Detergents, 12:7-19. DOI: $10.1007 / \mathrm{s} 11743-008-1092-4$

2. Alexandridis, P., Athanassiou, V., Fukuda, S. \& Hatton, T.A. (1994) Surface activity of poly(ethyleneoxide)-block-poly(propyleneoxide)-block-poly-(ethyleneoxide) copolymers. Langmuir, 10: 2604-2612. DOI: 10.1021/la00020a019

3. Ali, A.A. \& Mulley, B.A. (1978) Formation of liquid crystal and other non-fluid phases in emulsions containing non-ionic surfactants. Journal of Pharmacy and Pharmacology, 30: 205-213. DOI: 10.1111/j.2042-7158.1978.tb13206.x

4. Bardhan, S., Kundu, K., Kar, B., Chakraborty, G., Ghosh, D., Sarkar, D., Das, S., Senapati, S., Saha, S.K.\& Paul, B.K. (2016) Synergistic interactions of surfactant blends in aqueous medium are reciprocated in non-polar medium with improved efficacy as a nanoreactor. RSC Advances, 6: 55104-55116. DOI: 10.1039/C6RA06776J

5. Ben-Et, G. \& Tatarsky, D. (1972) Application of NMR for the determination of HLB values of nonionic surfactants. Journal of the American Oil Chemists' Society, 49: 499-500. DOI: 10.1007/BF02582488

6. Berger, B.W., García, R.Y, Lenhoff, A.M., Kaler, E.W. \& Robinson, C.R. (2005) Relating surfactant properties to activity and solubilization of the human adenosine A3 receptor. Biophysical Journal, 89: 452-464. DOI: 10.1529/biophysj.104.051417

7. Carless, J. E., Challis, R. A. \& Mulley, B. A. (1964) Nonionic surface-active agents. Part V. The effect of the alkyl and the polyglycol chain length on the critical micelle concentration of some monoalkyl polyethers. Journal of Colloid and Interface Science, 19:201-212. DOI: 10.1016/0095-8522(64)90014-5

8. Clunie, J. S., Corkill, J. M, Goodman, J. F., Symons, P. C. \& Tate, J. R. (1967) Thermodynamics of non-ionic surface-active agent + water systems. Transactions of the Faraday Society, 63: 2839-2845. DOI: 10.1039/TF9676302839

9. Crook, E. H., Trebbi, G. F. \& Fordyce, D. B. (1964) Thermodynamic Properties of Solutions of Homogeneous p,t-Octylphenoxyethoxyethanols (OPE1-10). The Journal of Physical Chemistry, 68: 3592-3599. DOI: 10.1021/j100794a026 
10. Davies, J.T. (1957) A quantitative kinetic theory of emulsion type, I. Physical chemistry of the emulsifying agent, gas/liquid and liquid/ liquid interface. In: Proceedings of the International Congress of Surface Activity, pp. 426-438.

11. Davis, H.T. (1994) Factors determining emulsion type: hydrophile-lipophile balance and beyond. Colloids and Surfaces A: Physicochemical and Engineering Aspects, 91:9-24. DOI: 10.1016/0927-7757(94)02929-6

12. Eastoe, J., Dalton, J. S., Rogueda, P. G. A., Crooks, E. R., Pitt, A. R. \& Simister, E. A. (1997) Dynamic surface tensions of nonionic surfactant solutions. Journal of Colloid and Interface Science, 188: 423-430. DOI: 10.1006/jcis.1997.4778

13. Elworthy, P. H. \& MacFarlane, C. B. (1962) Surface activity of a series of synthetic non-ionic detergents. Journal of Pharmacy and Pharmacology, 14: 100-102. DOI: 10.1111/j.2042-7158.1962.tb10540.x

14. Griffin, W.C. (1949) Classification of surface-active agents by “HLB”. Journal of the Society of Cosmetic Chemists, 1: 311-326.

15. Griffin, W.C. (1954) Calculation of HLB values of non-ionic surfactants. Journal of the Society of Cosmetic Chemists, 5: 249-256.

16. Hammouda, B.\& Ho D. L. (2007) Insight into chain dimensions in PEO/Water solutions. Journal of Polymer Science: Part B: Polymer Physics, 45: 2196-2200. DOI: 10.1002/polb.21221

17. Horozov, T.\& Joos, P. (1995) Dynamic surface tension of surfactant solutions studied by peak tensiometry. Journal of Colloid and Interface Science, 173:334-342. DOI: 10.1006/jcis.1995.1333

18. Huang, K.-L., Shigeta, K., Kunieda, H. (1998) Phase behavior of polyoxyethylene dodecyl ether-water systems. Progress in Colloid and Polymer Science, 110:171-174. DOI: $10.1007 / \mathrm{BFb} 0118071$

19. Huo, Q., Margolese, D.I. \& Stucky, G.D. (1996) Surfactant control of phases in the synthesis of mesoporous silica-based materials. Chemistry of Materials, 8:1147-1160. DOI: $10.1021 / \mathrm{cm} 960137 \mathrm{~h}$

20. Israelachvili, J. N., Mitchell, D. J. \& Ninham, B. W. (1976) Theory of self-assembly of hydrocarbon amphiphiles into micelles and bilayers. Journal of the Chemical Society Faraday Transactions, 72:1525-1568. DOI: 10.1039/F29767201525 
21. Kunieda, H. \& Shinoda, K. (1982) Phase behavior in systems of nonionic surfactant/ water/ oil around the hydrophile-lipophile-balance-temperature (HLB-temperature). Journal of dispersion Science and Technology, 3: 233-244. DOI: $10.1080 / 01932698208943639$

22. Kunieda, H. \& Shinoda, K. (1985) Evaluation of the Hydrophile-Lipophile Balance (HLB) of Nonionic Surfactants. I. Multisurfactant Systems. Journal of Colloid and Interface Science, 107: 107-121. DOI: 10.1016/0021-9797(85)90154-7

23. Kunieda, H., Shigeta,K., Ozawa, K., Suzuki M. (1997) Self-organizing structures in poly(oxyethylene) oleyl ether-water system. The Journal of Physical Chemistry B, 101: 7952-7957. DOI: 10.1021/jp9713322

24. Kunieda, H., Taoka, H.; Iwanaga, T. \& Harashima, A. (1998) Phase behavior of polyoxyethylene trisiloxane surfactant in water and water-oil. Langmuir, 14 :51135120. DOI: $10.1021 / \mathrm{la9} 80298 \mathrm{v}$

25. Kunieda, H., Umizu, G., Yamaguchi,Y.(1999) Mixing effect of polyoxyethylene-type nonionic surfactants on the liquid crystalline structures. Journal of Colloid and Interface Science, 218:88-96. DOI: 10.1006/jcis.1999.6400

26. Kunieda, H., Uddin, M.D., Horii, M., Furukawa, H. \& Harashima, A. (2001) Effect of hydrophilic- and hydrophobic-chain lengths on the phase behavior of A-B-type silicone surfactants in water. The Journal of Physical Chemistry B, 105: 5419-5426. DOI: $10.1021 / \mathrm{jp} 003314 \mathrm{~h}$

27. Kunieda, H., Akahane, A., Feng, J. \& Ishitobi, M. (2002) Phase behavior of polyglycerol didodecanoates in water. Journal of Colloid and Interface Science, 245: 365-370. DOI: 10.1006/jcis.2001.8000

28. Kunz, W., Testard, F., Zemb, T. (2009) Correspondence between curvature, packing parameter, and hydrophilic-lipophilic deviation scales around the phase-inversion temperature. Langmuir, 25: 112-115. DOI: 10.1021/1a8028879

29. Lang, J.C. \& Morgan, R.D. (1980) Nonionic surfactant mixtures. I. Phase equilibria in $\mathrm{C}_{10} \mathrm{E}_{4}-\mathrm{H}_{2} \mathrm{O}$ and closed-loop coexistence. The Journal of Chemical Physics, 73: 5849-5861. DOI: 10.1063/1.440028

30. Li, P.X., Li, Z.X., Shen, H-H. Thomas, R. K., Penfold, J. \& Lu, J.R. (2013) Application of the Gibbs equation to the adsorption of nonionic surfactants and 
polymers at the air-water interface: comparison with surface excesses determined directly using neutron reflectivity. Langmuir, 29: 9324-9334. DOI: 10.1021/la4018344

31. Liu, F., Wang, Z., Sun, D., Wei, X., Zhou, W., Li, G. \& Zhang, G. (2006) Adsorption kinetics of Brij 97 at the air/solution Interface. Journal of Dispersion Science and Technology, 27: 657-663. DOI: 10.1080/01932690600660624

32. Lu, J.R., Lee, E.M., Thomas, R.K., Penfold, J. \& Flitsch, S.L. (1993) Direct determination by neutron reflection of the structure of triethylene glycol monododecyl ether layers at the air/water interface. Langmuir, 9: 1352-1360. DOI: 10.1021/1a00029a032

33. Lu, J.R., Thomas, R.K. \& Penfold, J. (2000) Surfactant layers at the air/water interface: structure and composition. Advances in Colloid and Interface Science, 84:143-34. DOI: $10.1016 / \mathrm{S} 0001-8686(99) 00019-6$

34. Mahajan, R.K. \& Nandni, D. (2012) Micellization and phase behavior of binary mixtures of anionic and nonionic surfactants in aqueous media. Industrial \& Engineering Chemistry Research, 51: 3338-3349. DOI: 10.1021/ie202463w

35. Matos, S. L., Ravey, J.-C. \& Serratrice, G. (1989) Surface tension properties of aqueous new nonionic fluorinated surfactants. Journal of Colloid and Interface Science, 128: 341-347. DOI: 10.1016/0021-9797(89)90348-2

36. Meguro, K., Takasawa, Y., Kawahasi, N., Tabata, Y. \& Ueno, M. (1981) Micellar properties of a series of octaethyleneglycol-n-alkyl ethers with homogeneous ethylene oxide chain and their temperature dependence. Journal of Colloid Interface Science, 83: 50-56. DOI: 10.1016/0021-9797(81)90008-4

37. Nagarajan, R. (2002) Molecular packing parameter and surfactant self-assembly: the neglected role of the surfactant tail. Langmuir, 18: 31-38. DOI: 10.1021/la010831y

38. Nibu, Y., Suemori, T., Inoue, T. (1997) Phase behavior of binary mixture of heptaethylene glycol decyl ether and water: formation of phase compound in solid phase. Journal of Colloid Interface Science, 191:256-263. DOI: $10.1006 /$ jcis. 1997.4941 
39. Nibu, Y., Inoue, T. (1998) Phase behavior of aqueous mixtures of some polyethylene glycol decyl ethers revealed by DSC and FT-IR measurements. Journal of Colloid and Interface Science, 205: 305-315. DOI: 10.1006/jcis.1998.5621

40. Nikas, Y. J., Puvvada, S. \& Blankschtein, D. (1992) Surface tensions of aqueous nonionic surfactant mixtures. Langmuir, 8: 2680-2689. DOI: 10.1021/la00047a018

41. Pollard, M.L., Pan, R., Steiner, C. \& Maldarelli, C. (1998) Phase behavior of sparingly soluble polyethoxylate monolayers at the air-water surface and its effect on dynamic tension. Langmuir, 14: 7222-7234. DOI: 10.1021/la970236p

42. Queste, S., Salager, J. L., Strey, R.\& Aubry, J. M. (2007) The EACN scale for oil classification revisited thanks to fish diagrams. Journal of Colloid Interface Science, 312: 98-107. DOI: 10.1016/j.jcis.2006.07.004

43. Rabaron, A., Cavé, G., Puisieux, F. \& Seiller, M. (1993) Physical methods for measurement of the HLB of ether and ester non-ionic surface-active agents: H-NMR and dielectric constant. International Journal of Pharmaceutics, 99: 29-36. DOI: 10.1016/0378-5173(93)90319-B

44. Rodríguez-Abreu, C. \& Vila, A. (2014) Nano-droplet systems by surfactant selfassembly and applications in the pharmaceutical industry. Current Topics in Medicinal Chemistry, 14: 747-765. DOI: 10.2174/1568026614666140118221658

45. Rosen, M. J., Cohen, A. W., Dahanayake, M. \& Hua, X.-Y. (1982) Relationship of structure to properties in surfactants. 10. Surface and thermodynamic properties of 2dodecyloxypoly(ethenoxyethanol)s, $\mathrm{C}_{12} \mathrm{H}_{25}\left(\mathrm{OC}_{2} \mathrm{H}_{4}\right)_{\mathrm{x}} \mathrm{OH}$, in aqueous solution. The Journal of Physical Chemistry, 86, 541-545. DOI: 10.1021/j100393a025

46. Sakya, P., Seddon, J. M., Templer, R. H., Mirkin, R. J. \& Tiddy, G. J. T. (1997) Micellar cubic phases and their structural relationships: the nonionic surfactant system $\mathrm{C}_{12} \mathrm{EO}_{12} /$ Water. Langmuir, 13: 3706-3714. DOI: 10.1021/la9701844

47. Salager, J.-L. Marquez, N., Graciaa, A. \& Lachaise, J. (2000) Partitioning of ethoxylated octylphenol surfactants in microemulsion-oil-water systems: influence of temperature and relation between partitioning coefficient and physicochemical formulation. Langmuir, 16: 5534-5539. DOI: 10.1021/la9905517 
48. Samanta, S. \& Ghosh, P. (2011) Coalescence of bubbles and stability of foams in brij surfactant systems. Industrial \& Engineering Chemistry Research, 50: 4484-4493. DOI: $10.1021 / \mathrm{ie} 102396 \mathrm{v}$

49. Sedev, R. (2001) Limiting area per molecule of nonionic surfactants at the water/air interface. Langmuir, 17:562-564. DOI: 10.1021/la000572x

50. Sottmann, T, Strey, R.\& Chen, S.-H. (1997) A small-angle neutron scattering study of nonionic surfactant molecules at the water-oil interface: area per molecule, microemulsion domain size, and rigidity. The Journal Chemical Physics, 106: 64836491. DOI: $10.1063 / 1.473638$

51. Strey, R., Schomäcker, R., Roux, D., Nallet, F. \& Olsson, U. (1990) Dilute lamellar and $\mathrm{L}_{3}$ phases in the binary water- $\mathrm{C}_{12} \mathrm{E}_{5}$ system. Journal of the Chemical Society, Faraday Transactions, 86: 2253-2261. DOI: 10.1039/FT9908602253

52. Tanford, C. (1972) Micelle shape and size. The Journal of Physical Chemistry, 76: 3020-3024. DOI: $10.1021 / \mathrm{j} 100665 \mathrm{a} 018$

53. van Voorst Vader, F. (1960) Adsorption of detergents at the liquid-liquid interface. Part 2. Transactions of the Faraday Society, 56: 1078-1084. DOI: 10.1039/TF9605601078

54. Wang, Z., Liu, F., Zhang, Q., Wei, X., Sun, D., Li, G. \& Zhang, G. (2005) Adsorption kinetics of Brij 35 at air/solution interface. Indian Journal of Chemistry, 44A: 20512054. 
Tables

Table 1. Best fittings to the equation $a_{\mathrm{s}}=k n^{x}$ (air/water interface) for concentrations below or at $\mathrm{CMC}\left(25^{\circ} \mathrm{C}\right)$

\begin{tabular}{|c|c|c|c|c|c|}
\hline Surfactant series & $n$ & $\boldsymbol{k}$ & $x$ & $R^{2}$ & References \\
\hline $\mathrm{C}_{10} \mathrm{EO}_{n}^{\mathrm{a}, \mathrm{b}}$ & $4,5,6,8,10$ & 17.24 & 0.65 & 0.9643 & $\begin{array}{l}\text { Mahajan et al, } \\
2012 \\
\text { Eastoe et al, } \\
1997 \\
\text { Carless et al, } \\
1964 \\
\text { Meguro et } \\
\text { al,1981 }\end{array}$ \\
\hline $\mathrm{C}_{12} \mathrm{EO}_{n}^{\mathrm{a}, \mathrm{b}}$ & $2,3,4,5,6,7,8,12$ & 23.51 & 0.46 & 0.9234 & $\begin{array}{l}\text { Lu et al, } 1993 \\
\text { Lu et al, } 2000 \\
\text { Li et al, } 2013 \\
\text { Rosen et al, } \\
1982 \text { a } \\
\text { Eastoe et al, } \\
1997\end{array}$ \\
\hline $\mathrm{C}_{14} \mathrm{EO}_{n}{ }^{\mathrm{a}, \mathrm{b}}$ & $1,2,4,6,8$ & 18.40 & 0.44 & 0.9565 & $\begin{array}{l}\text { Pollard et al, } \\
1998 \\
\text { Meguro et } \\
\text { al,1981 }\end{array}$ \\
\hline $\mathrm{C}_{16} \mathrm{EO}_{n}{ }^{\mathrm{a}, \mathrm{b}}$ & $2,4,6,7,9,12,15,21,20,30,40$ & 11.51 & 0.72 & 0.9841 & $\begin{array}{l}\text { Pollard et al, } \\
1998 \\
\text { Elworthy et al, } \\
1962\end{array}$ \\
\hline $\mathrm{OPEO}_{n}{ }^{\mathrm{c}}$ & $3,4,5,6,7,8,9,10$ & 29.10 & 0.38 & 0.9586 & $\begin{array}{l}\text { Crook et al, } \\
1964\end{array}$ \\
\hline $\mathrm{C}_{6} \mathrm{~F}_{13} \mathrm{EO}_{n}{ }^{\mathrm{d}}$ & $2,3,5,7$ & 26.99 & 0.33 & 0.9673 & $\begin{array}{l}\text { Matos et al, } \\
1989\end{array}$ \\
\hline $\mathrm{EO}_{n} \mathrm{PO}_{50-60} \mathrm{EO}_{n} \mathrm{e}$ & $17,27,37,132$ & 19.03 & 0.43 & 0.9739 & $\begin{array}{l}\text { Alexandridis } \\
\text { et al, } 1994\end{array}$ \\
\hline Brij $^{\mathrm{TM}}$ series ${ }^{\mathrm{f}}$ & $2,4,5,10,12,20,21,23,25$ & 12.41 & 0.69 & 0.9374 & $\begin{array}{l}\text { Wang et al, } \\
2005 \\
\text { Liu et al, } 2006 \\
\text { Horozov et al, } \\
1995 \\
\text { Bardhan et al, } \\
2016 \\
\text { Samanta et al, } \\
2011\end{array}$ \\
\hline
\end{tabular}

${ }^{\mathrm{a}} \mathrm{C}_{\mathrm{j}}=\mathrm{C}_{\mathrm{j}} \mathrm{H}_{2 \mathrm{j}+1} ;{ }^{\mathrm{b}} \mathrm{EO}_{n}=\left(\mathrm{OC}_{2} \mathrm{H}_{4}\right)_{n} \mathrm{OH} ;{ }^{\mathrm{c}} \mathrm{OP}=$ octyl phenol; ${ }^{\mathrm{d}} \mathrm{C}_{6} \mathrm{~F}_{13}=\mathrm{C}_{6} \mathrm{~F}_{13} \mathrm{C}_{2} \mathrm{H}_{4} \mathrm{SC}_{2} \mathrm{H}_{4}$

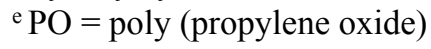

${ }^{\mathrm{f}}$ Fitted data correspond to Brij 30,35,56,58,72,76,78,93,97, 98 and 721 (they have different alkyl chain length). 
Table 2. Best fittings to the equation $a=k n^{x}$ (aggregate's surface) for concentrations at which liquid crystals are formed in water at $25^{\circ} \mathrm{C}$

\begin{tabular}{|c|c|c|c|c|l|}
\hline Surfactant series & $\boldsymbol{n}$ & $\boldsymbol{k}$ & $\boldsymbol{x}$ & $\boldsymbol{R}^{\mathbf{2}}$ & References \\
\hline $\mathrm{C}_{12} \mathrm{EO}_{\mathrm{n}}$ & $2,3,4,6,7,8,9,12$ & 26.82 & 0.31 & 0.9845 & $\begin{array}{l}\text { Kunieda et } \\
\text { al (1999); } \\
\text { Sakya et al } \\
(1997)\end{array}$ \\
\hline $\mathrm{C}_{18: 1} \mathrm{EO}_{\mathrm{n}}$ & $2-20^{a}$ & 27.39 & 0.29 & 0.9566 & $\begin{array}{l}\text { Kunieda et } \\
\text { al (1997) }\end{array}$ \\
\hline $\mathrm{Si}_{3} \mathrm{EO}_{\mathrm{n}}$ & $6-10^{a}$ & 25.56 & 0.33 & 0.9240 & $\begin{array}{l}\text { Kunieda et } \\
\text { al (1998) }\end{array}$ \\
\hline
\end{tabular}

${ }^{a}$ surfactants with different $n$ were mixed to obtain average $\bar{n}$ values within the indicated range.

$\mathrm{C}_{18: 1}=$ oleyl chain. $\mathrm{Si}_{3}=$ trisiloxane.

Table 3: Best fittings of data in Fig.2 to the equation $P=b \mathrm{HLB}+c$

\begin{tabular}{|l|c|c|c|}
\hline Surfactant series & $\boldsymbol{b}$ & $\boldsymbol{c}$ & $\boldsymbol{R}^{\mathbf{2}}$ \\
\hline $\mathrm{C}_{10} \mathrm{EO}_{\mathrm{n}}$ & -0.0535 & 1.0492 & 0.9390 \\
\hline $\mathrm{C}_{12} \mathrm{EO}_{\mathrm{n}}$ & -0.0382 & 0.8345 & 0.9849 \\
\hline $\mathrm{C}_{14} \mathrm{EO}_{\mathrm{n}}$ & -0.0721 & 1.3196 & 0.9780 \\
\hline $\mathrm{C}_{16} \mathrm{EO}_{\mathrm{n}}$ & -0.0711 & 1.2889 & 0.9939 \\
\hline $\mathrm{OPEO}_{\mathrm{n}}$ & -0.0411 & 0.9853 & 0.9757 \\
\hline $\begin{array}{l}\text { Alkyl } \\
\text { polyglucosides }\end{array}$ & -0.0121 & 0.5671 & 0.9669 \\
\hline Brij $^{\mathrm{TM}}$ series & -0.0836 & 1.5059 & 0.9321 \\
\hline
\end{tabular}




\section{Figure legends:}

Figure 1. Plot of interfacial area $a$ as a function of ethylene oxide number $n$ for $\mathrm{C}_{12} \mathrm{EO}_{n}$ surfactant series. Data are derived from SAXS measurements in lamellar $(n=2,3,4)$ and hexagonal $(n=6,7,8,9)$ liquid crystals in water. The water/ethylene oxide weight ratio is constant at 1.25. Data from Kunieda et al (1999)

Figure 2. Plot of packing parameter $P$ versus HLB for various series of nonionic surfactants

Figure 3. Phase diagrams of $\mathrm{C}_{\mathrm{j}} \mathrm{EO}_{n}$ surfactants in water as a function of $\mathrm{HLB}, n$ and surfactant concentration at $25^{\circ} \mathrm{C}$. (a) $\mathrm{j}=12$ (b) $\mathrm{j}=12$ (c) $\mathrm{j}=16$ (d) $\mathrm{j}=18: 1$ (oleyl chain). Diagrams (a) and (c) have been built using data from Clunie et al (1967), Ali\& Mulley (1978), Lang\&Morgan (1980), Nibu et al (1997), Huang et al (1998), and Nibu \& Inoue (1998). Diagram (b) is adapted by permission from Springer, Progress in Colloid and Polymer Science 110:171-174, "Phase behavior of polyoxyethylene dodecyl ether-water systems", Huang et al, Copyright (1998). Diagram (d) is adapted with permission from Kunieda et al, The Journal of Physical Chemistry B, 101: 7952-7957, Copyright (1997) American Chemical Society.

Fig.4 Boundaries for morphological transitions in $\mathrm{C}_{\mathrm{j}} \mathrm{EO}_{n}$ surfactants (a) layer-to-cylinder transition $(P=1$ to $1 / 2)$ (b) cylinder-to-sphere transition $(P=1 / 2$ to $1 / 3) . \mathrm{C}_{18: 1}$ denotes an oleyl chain.

Fig.5 Phase diagrams of (a) trisiloxane-EO and (b) poly(dimethylsiloxane)-EO surfactants in water as a function of HLB, $n$ and surfactant concentration at $25{ }^{\circ} \mathrm{C}$. The diagrams are adapted with permission from Kunieda et al, Langmuir, 14:5113-5120, Copyright (1998) American Chemical Society and Kunieda et al, The Journal of Physical Chemistry B, 105:5419-5426, Copyright (2001) American Chemical Society. $\mathrm{Si}_{3}=$ trisiloxane; $\mathrm{Si}_{14}=\left(\mathrm{CH}_{3}\right)$ ${ }_{3} \mathrm{SiO}\left(\left(\mathrm{CH}_{3}\right)_{2} \mathrm{SiO}\right)_{12}\left(\mathrm{CH}_{3}\right)_{2} \mathrm{SiCH}_{2} \mathrm{CH}_{2} \mathrm{CH}_{2}$

Figure 6 Phase diagram polyglyceryl didodecanoate $\left(\mathrm{C}_{11}\right)_{2} \mathrm{G}_{n}$ surfactants in water as a function of HLB, $n$ and surfactant concentration at $25{ }^{\circ} \mathrm{C}$. The diagram is adapted from Journal of Colloid and Interface Science, 245, Kunieda et al "Phase Behavior of Polyglycerol Didodecanoates in Water", pp. 365-370, Copyright (2002) with permission from Elsevier. 


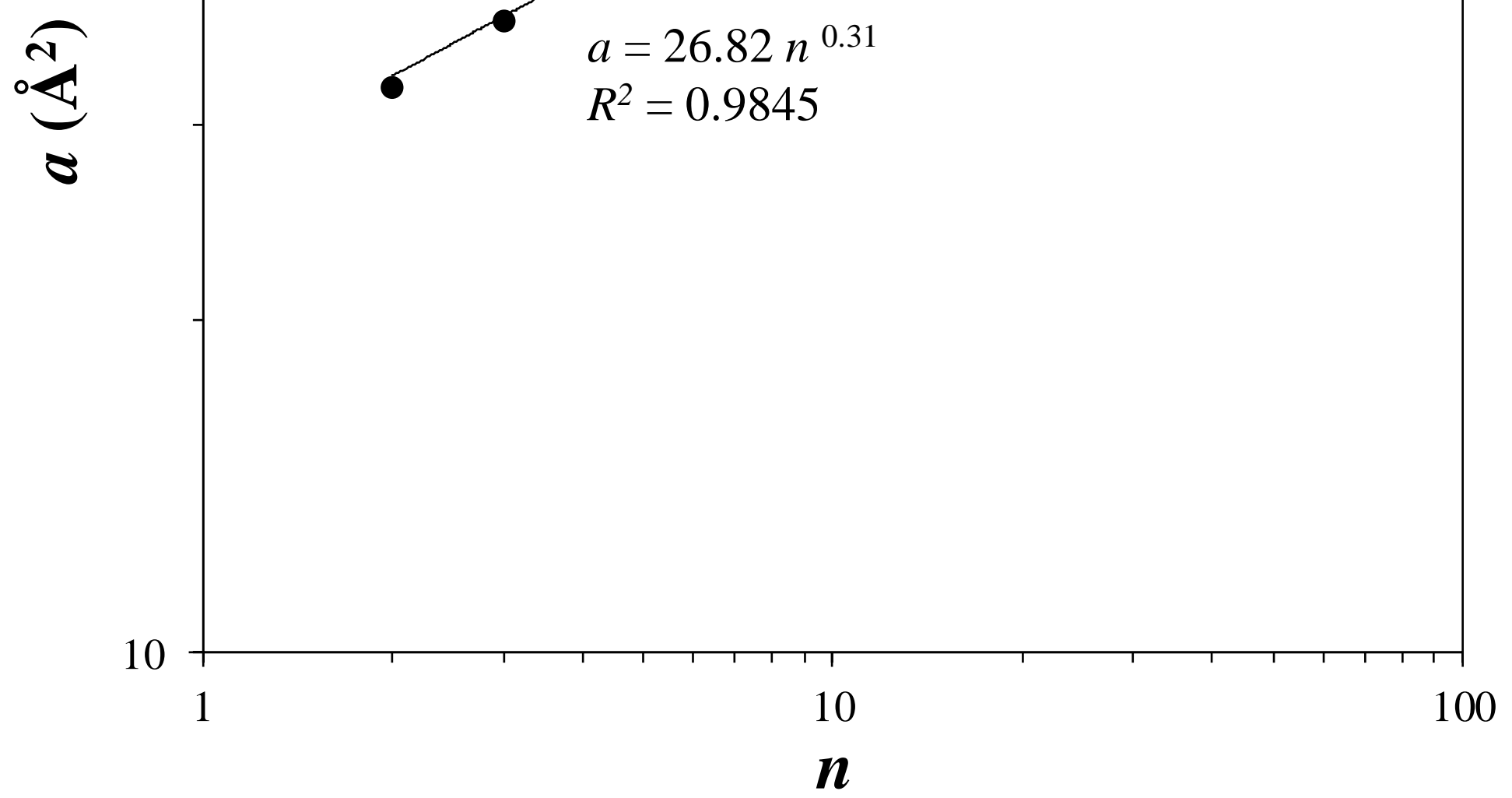

Figure 1 


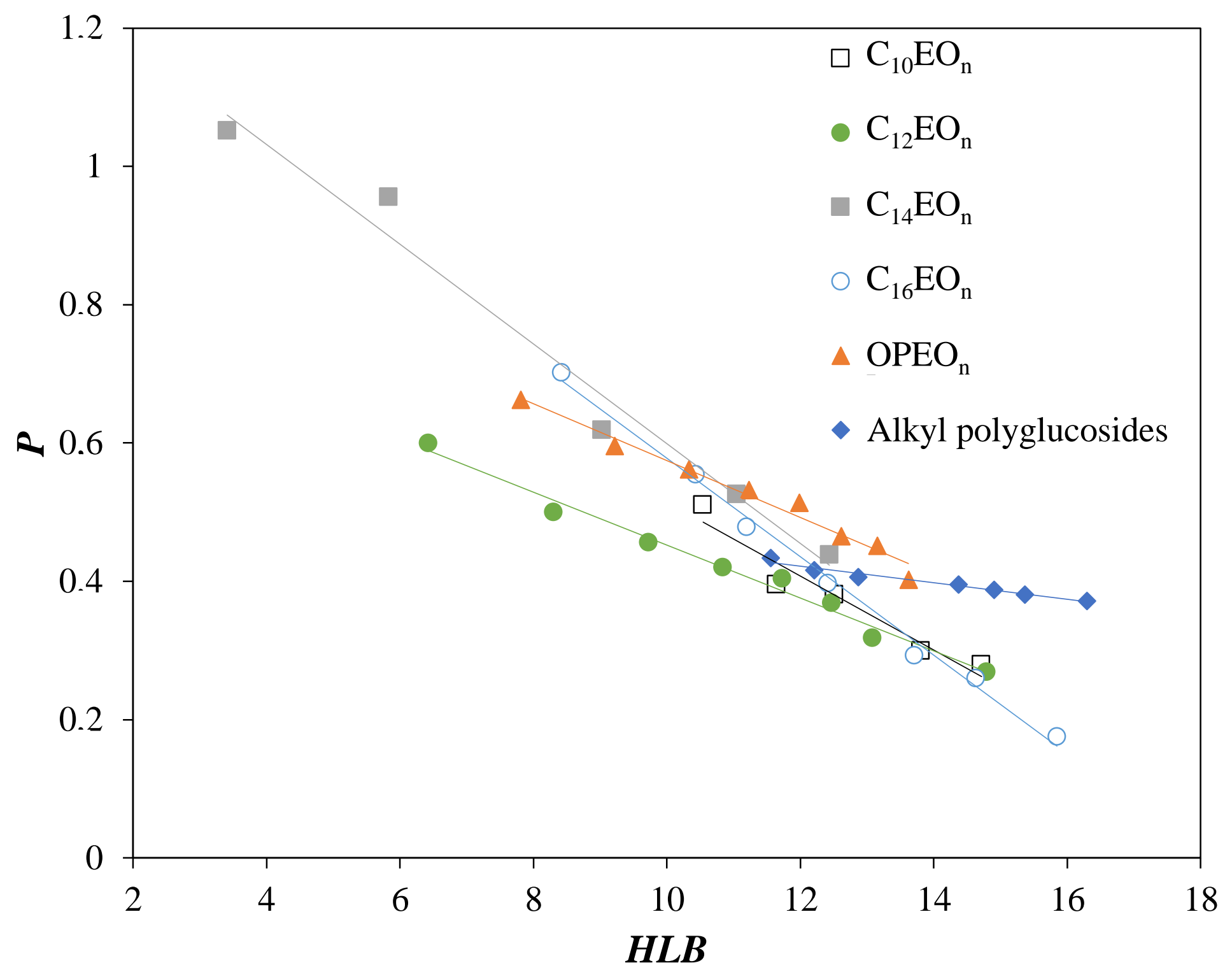

Figure 2 
(a)

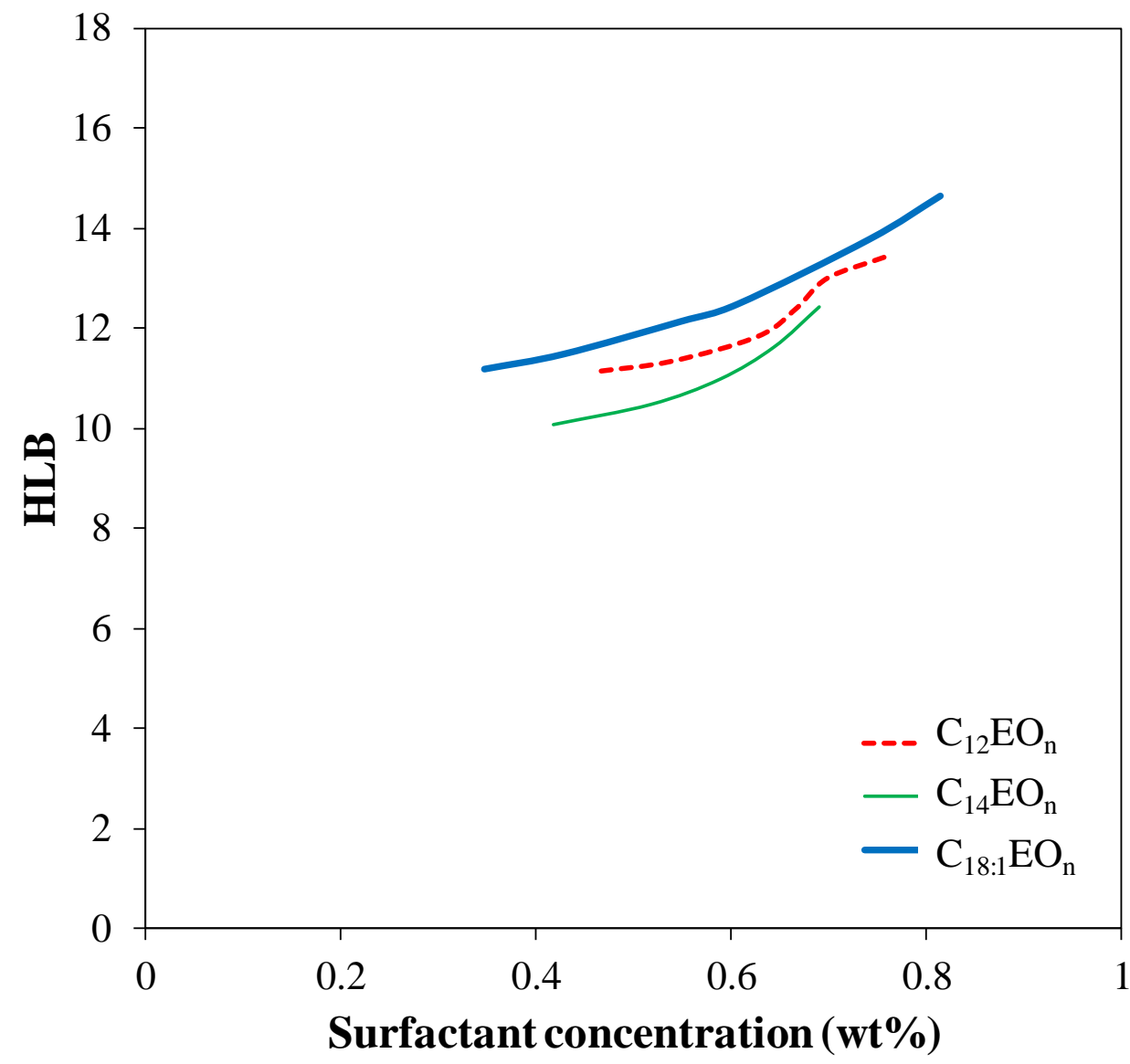

(b)

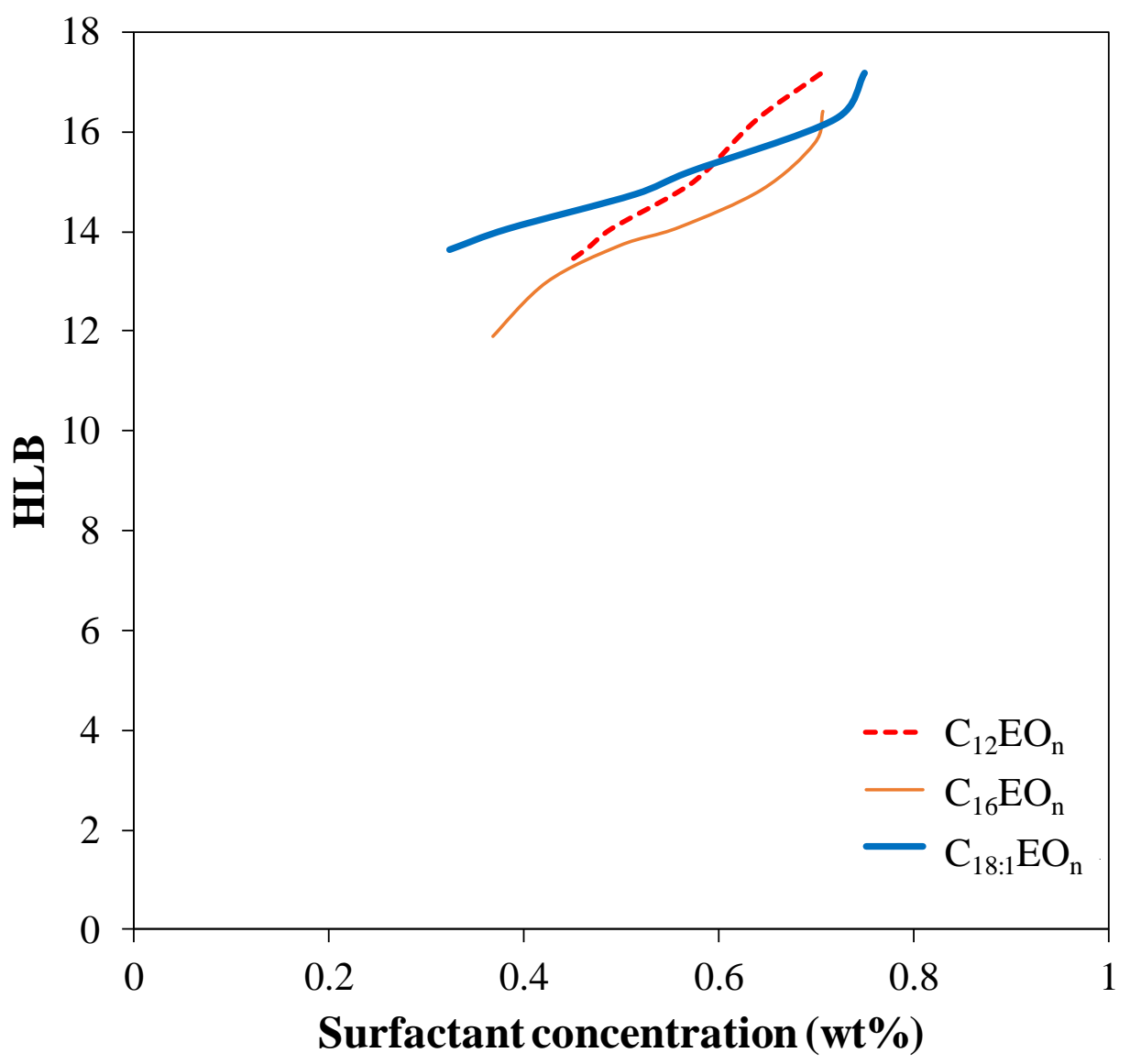

Figure 4 
(a)

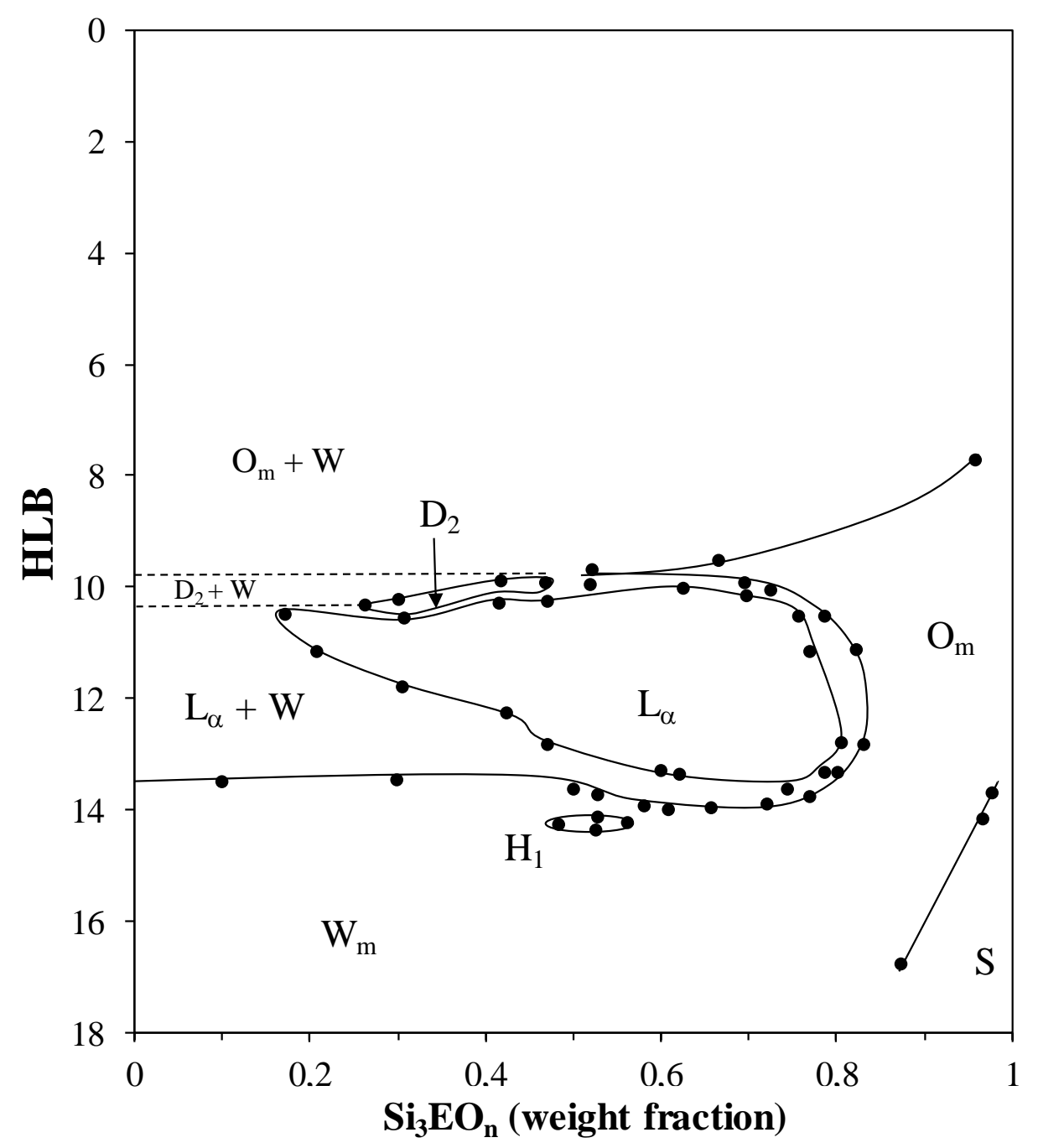

(b)

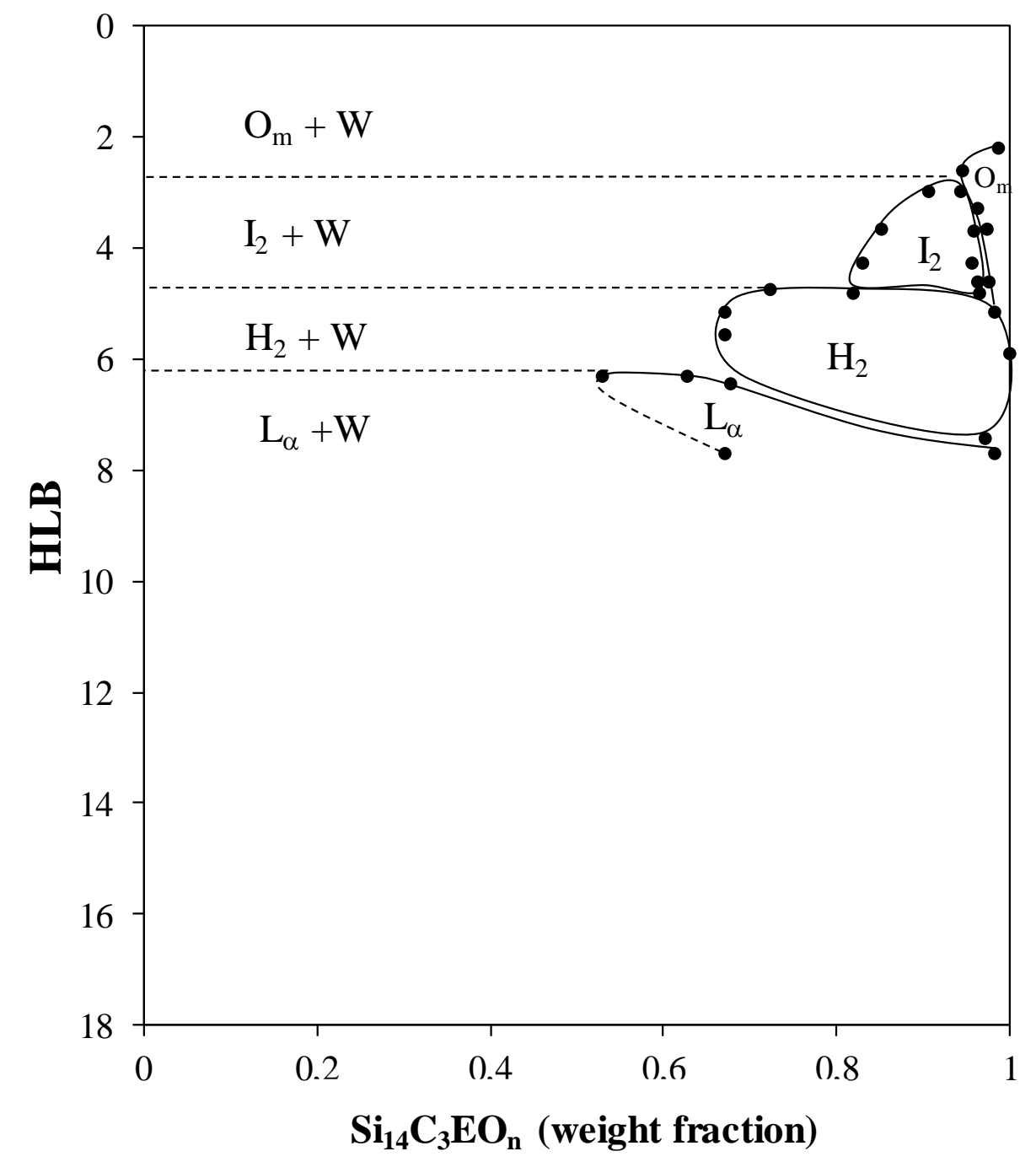

Figure 5 


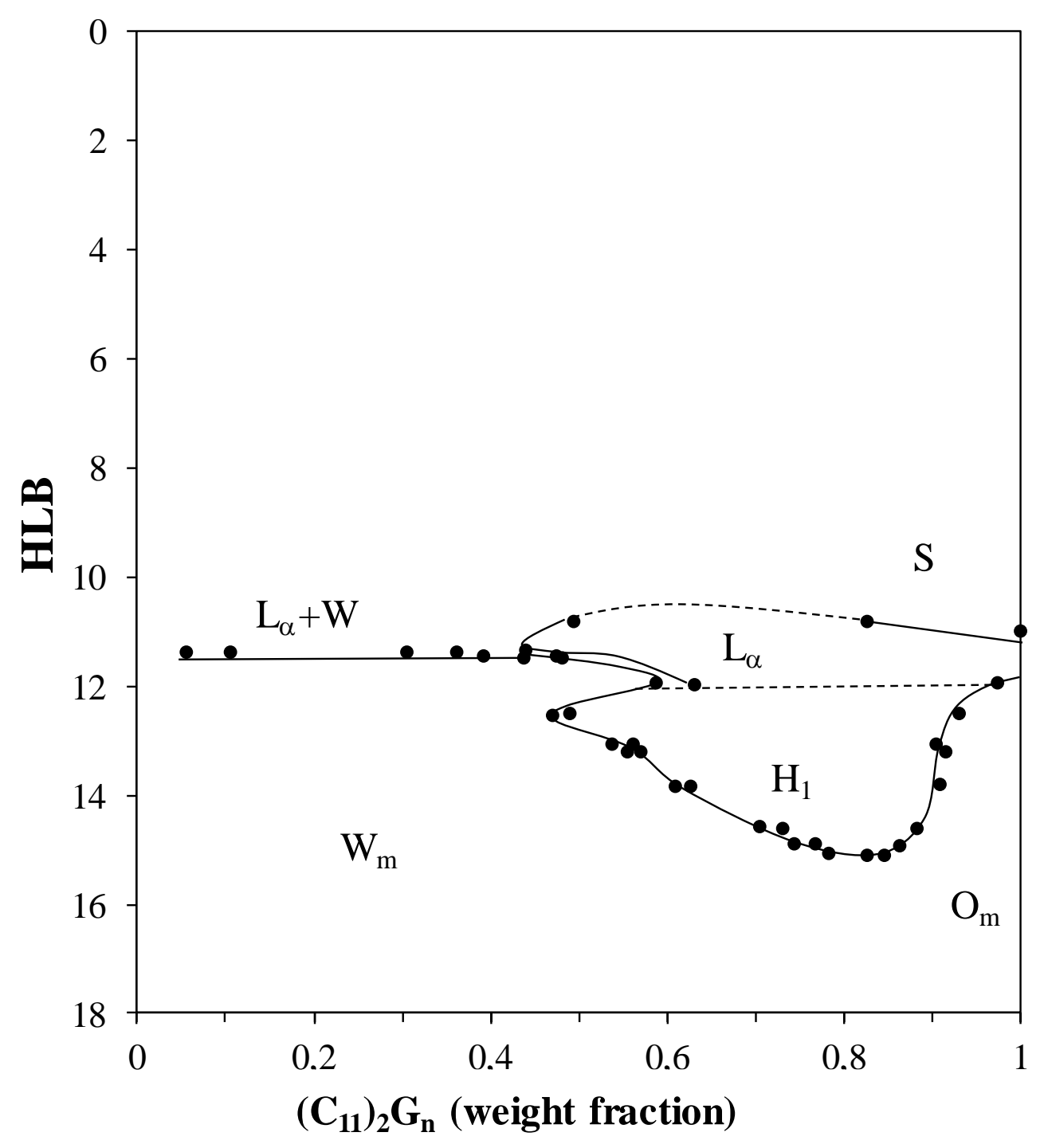

Figure 6 
Table 1. Best fittings to the equation $a_{\mathrm{s}}=k n^{x}$ (air/water interface) for concentrations below or at $\mathrm{CMC}\left(25^{\circ} \mathrm{C}\right)$

\begin{tabular}{|c|c|c|c|c|c|}
\hline Surfactant series & $n$ & $\boldsymbol{k}$ & $x$ & $R^{2}$ & References \\
\hline $\mathrm{C}_{10} \mathrm{EO}_{n}{ }^{\mathrm{a}, \mathrm{b}}$ & $4,5,6,8,10$ & 17.24 & 0.65 & 0.9643 & $\begin{array}{l}\text { Mahajan et al, } \\
2012 \\
\text { Eastoe et al, } \\
1997 \\
\text { Carless et al, } \\
1964 \\
\text { Meguro et } \\
\text { al,1981 }\end{array}$ \\
\hline $\mathrm{C}_{12} \mathrm{EO}_{n}^{\mathrm{a}, \mathrm{b}}$ & $2,3,4,5,6,7,8,12$ & 23.51 & 0.46 & 0.9234 & $\begin{array}{l}\text { Lu et al, } 1993 \\
\text { Lu et al, } 2000 \\
\text { Li et al, } 2013 \\
\text { Rosen et al, } \\
1982 \mathrm{a} \\
\text { Eastoe et al, } \\
1997\end{array}$ \\
\hline $\mathrm{C}_{14} \mathrm{EO}_{n}^{\mathrm{a}, \mathrm{b}}$ & $1,2,4,6,8$ & 18.40 & 0.44 & 0.9565 & $\begin{array}{l}\text { Pollard et al, } \\
1998 \\
\text { Meguro et } \\
\text { al,1981 }\end{array}$ \\
\hline $\mathrm{C}_{16} \mathrm{EO}_{n}^{\mathrm{a}, \mathrm{b}}$ & $2,4,6,7,9,12,15,21,20,30,40$ & 11.51 & 0.72 & 0.9841 & $\begin{array}{l}\text { Pollard et al, } \\
1998 \\
\text { Elworthy et al, } \\
1962 \\
\end{array}$ \\
\hline $\mathrm{OPEO}_{n}{ }^{\mathrm{c}}$ & $3,4,5,6,7,8,9,10$ & 29.10 & 0.38 & 0.9586 & $\begin{array}{l}\text { Crook et al, } \\
1964\end{array}$ \\
\hline $\mathrm{C}_{6} \mathrm{~F}_{13} \mathrm{EO}_{n}{ }^{\mathrm{d}}$ & $2,3,5,7$ & 26.99 & 0.33 & 0.9673 & $\begin{array}{l}\text { Matos et al, } \\
1989\end{array}$ \\
\hline $\mathrm{EO}_{n} \mathrm{PO}_{50-60} \mathrm{EO}_{n}{ }^{\mathrm{e}}$ & $17,27,37,132$ & 19.03 & 0.43 & 0.9739 & $\begin{array}{l}\text { Alexandridis } \\
\text { et al, } 1994\end{array}$ \\
\hline Brij $^{\mathrm{TM}}$ series $^{\mathrm{f}}$ & $2,4,5,10,12,20,21,23,25$ & 12.41 & 0.69 & 0.9374 & \begin{tabular}{|l} 
Wang et al, \\
2005 \\
Liu et al, 2006 \\
Horozov et al, \\
1995 \\
Bardhan et al, \\
2016 \\
Samanta et al, \\
2011
\end{tabular} \\
\hline
\end{tabular}

${ }^{\mathrm{f}}$ Fitted data correspond to Brij 30,35,56,58,72,76,78,93,97, 98 and 721 (they have different alkyl chain length). 
Table 2. Best fittings to the equation $a=k n^{x}$ (aggregate's surface) for concentrations at which liquid crystals are formed in water at $25^{\circ} \mathrm{C}$

\begin{tabular}{|c|c|c|c|c|l|}
\hline Surfactant series & $\boldsymbol{n}$ & $\boldsymbol{k}$ & $\boldsymbol{x}$ & $\boldsymbol{R}^{\mathbf{2}}$ & References \\
\hline $\mathrm{C}_{12} \mathrm{EO}_{\mathrm{n}}$ & $2,3,4,6,7,8,9,12$ & 26.82 & 0.31 & 0.9845 & $\begin{array}{l}\text { Kunieda et } \\
\text { al (1999); } \\
\text { Sakya et al } \\
(1997)\end{array}$ \\
\hline $\mathrm{C}_{18: 1} \mathrm{EO}_{\mathrm{n}}$ & $2-20^{a}$ & 27.39 & 0.29 & 0.9566 & $\begin{array}{l}\text { Kunieda et } \\
\text { al (1997) }\end{array}$ \\
\hline $\mathrm{Si}_{3} \mathrm{EO}_{\mathrm{n}}$ & $6-10^{a}$ & 25.56 & 0.33 & 0.9240 & $\begin{array}{l}\text { Kunieda et } \\
\text { al (1998) }\end{array}$ \\
\hline
\end{tabular}

${ }^{a}$ surfactants with different $n$ were mixed to obtain average $\bar{n}$ values within the indicated range. $\mathrm{C}_{18: 1}=$ oleyl chain. $\mathrm{Si}_{3}=$ trisiloxane . 
Table 3: Best fittings of data in Fig.2 to the equation $P=b \mathrm{HLB}+c$

\begin{tabular}{|l|c|c|c|}
\hline Surfactant series & $\boldsymbol{b}$ & $\boldsymbol{c}$ & $\boldsymbol{R}^{\mathbf{2}}$ \\
\hline $\mathrm{C}_{10} \mathrm{EO}_{\mathrm{n}}$ & -0.0535 & 1.0492 & 0.9390 \\
\hline $\mathrm{C}_{12} \mathrm{EO}_{\mathrm{n}}$ & -0.0382 & 0.8345 & 0.9849 \\
\hline $\mathrm{C}_{14} \mathrm{EO}_{\mathrm{n}}$ & -0.0721 & 1.3196 & 0.9780 \\
\hline $\mathrm{C}_{16} \mathrm{EO}_{\mathrm{n}}$ & -0.0711 & 1.2889 & 0.9939 \\
\hline $\mathrm{OPEO}_{\mathrm{n}}$ & -0.0411 & 0.9853 & 0.9757 \\
\hline $\begin{array}{l}\mathrm{Alkyl} \\
\text { polyglucosides }\end{array}$ & -0.0121 & 0.5671 & 0.9669 \\
\hline Brij & & & \\
\hline
\end{tabular}

